\title{
Knowledge of childhood burn risks and burn first aid: Cool Runnings
}

\author{
Jacqueline D Burgess, ${ }^{1,2,3}$ Kerrianne A Watt, ${ }^{4}$ Roy M Kimble, ${ }^{1,3,5}$ Cate M Cameron ${ }^{6,7}$
}

${ }^{1}$ Centre for Children's Burns and Trauma Research, University of Queensland, Children's Health Research Centre, Brisbane,

Australia

${ }^{2}$ Wound Management Innovation Cooperative Research Centre, Brisbane, Australia

${ }^{3}$ Pegg Leditschke Children's Burns Centre, Lady Cilento Childen's Hospital, Brisbane, Australia

${ }^{4}$ College of Public Health, Medical and Veterinary Sciences, lames Cook University, Townsville, Australia ${ }^{5}$ Department of Paediatric Surgery, Urology Burns and Trauma Unit, Lady Cilento Children's Hospital, Brisbane, Australia

${ }^{6}$ The Jamieson Trauma Institute, Metro North Hospital and Health Service District, Herston, Australia

${ }^{7}$ The Hopkins Centre, Menzies Health Institute Queensland, Griffith University, Meadowbrook, Australia

Correspondence to Jacqueline D Burgess, Centre for Children's Burns and Trauma Research, University of Queensland, Children'sHealth Research Centre, Brisbane, QLD 4101, Australia; jacquii@uq. edu.au

Received 31 October 2017 Revised 25 December 2017 Accepted 27 December 2017

Check for updates

To cite: Burgess JD, Watt KA, Kimble RM, et al.Inj Prev Epub ahead of print: [please include Day Month Yearl. doi:10.1136

injuryprev-2017-042650

\section{ABSTRACT}

Aim The high incidence of hot beverage scalds among young children has not changed in the past 15 years, but preventive campaigns have been scarce. A novel approach was used to engage mothers of young children in an app-based hot beverage scald prevention campaign 'Cool Runnings'. This paper provides baseline data for this randomised controlled trial (RCT).

Method Queensland-based mothers aged 18+ years with at least one child aged 5-12 months were recruited via social media to Cool Runnings, which is a two-group, parallel, single-blinded RCT.

Results In total, 498 participants from across Queensland completed the baseline questionnaire. The most common source of burn first aid information was the internet (79\%). One-third (33\%) correctly identified hot beverage scalds as the leading cause of childhood burns, 43\% knew the age group most at risk. While $94 \%$ reported they would cool a burn with water, only $10 \%$ reported the recommended 20 min duration. After adjusting for all relevant variables, there were two independent predictors of adequate burn first aid knowledge: first aid training in the past year $(\mathrm{OR}=3.32$; $95 \% \mathrm{Cl} 1.8$ to 6.1$)$ and smoking status $(\mathrm{OR}=0.17 ; 95 \%$ $\mathrm{Cl} 0.04$ to 0.7$)$.

Conclusion In this study, mothers of young children were largely unaware how frequently hot beverage scalds occur and the age group most susceptible to them. Inadequate burn first aid knowledge is prevalent across mothers of young children; there is an urgent and compelling need to improve burn first aid knowledge in this group. Given the high incidence of hot beverages scalds in children aged 6-24 months, it is important to target future burn prevention/first aid campaigns at parents of young children.

Trial registration number ACTRN12616000019404; Pre-results.

\section{BACKGROUND}

Hot beverage scalds, like most injuries, are preventable. Yet, these specific injuries have been largely overlooked in injury prevention campaigns, often forming part of broader scald prevention campaigns that tend to focus on hot tap water/bathroom scalds. $^{12}$

In Australia, hot beverage scalds account for $18 \%$ of all burns to children-a figure that has remained constant for the past decade. ${ }^{3}$ Another constant is the poor knowledge of correct burn first aid in the general public. ${ }^{4}$ The literature shows that many burn victims, particularly children, receive incorrect or inadequate first aid treatment at the scene, with some receiving no treatment at all. $^{6-8}$ The continued high incidence of hot beverage scalds and low use of correct burn first aid use lead to unnecessary physical suffering, and for severe scalds, an economic burden to both the family and healthcare system.

The aetiology of hot beverage scalds is well documented, with injuries peaking in children aged 6-24 months, the majority occurring in the child's home, and the most common mechanism being the child pulling a cup of hot liquid down over themselves. $^{39} 10$

The aim of this paper is to (1) assess the current level of knowledge about burn risks and burn first aid in mothers of young children in Queensland, Australia, and (2) to determine factors that predict adequate versus inadequate burn first aid knowledge in this population.

\section{METHODS}

Participants in this study are mothers of young children (5-12 months) residing in Queensland, Australia, who enrolled in the Cool Runnings randomised controlled trial (RCT). Cool Runnings is a 6-month smartphone application-based hot beverage scald prevention intervention that was developed to improve knowledge about burn risks and burn first aid in mothers of young children, ${ }^{11}$ given that they are the age group most at risk of hot beverage scalds. The data presented here are the baseline data from the RCT but represent a cross-sectional sample of mothers of young children in Queensland. Detailed methods for this RCT have been previously published in a protocol paper. ${ }^{11}$ To be eligible for the study, participants were required to be: female, aged $18+$ years, resident in Queensland, Australia, with at least one child aged 5-12 months at enrolment and own a smartphone. Participants were recruited via social media, specifically Facebook and Instagram. Participants who met the inclusion criteria were invited to download the Cool Runnings smartphone application (app). Data were collected via the Cool Runnings app.

\section{Data collection}

Participants completed a 19-item questionnaire that took 5-8 $\mathrm{min}$ to complete. Items included demographic factors (such as education level, age of youngest child, number of children, relationship status and smoking status) and their residential postcode. Postcodes were recoded using Accessibility/Remoteness Index of Australia (ARIA) ${ }^{12} 13$ and Socio-Economic Index for Areas (SEIFA) as measures social disadvantage. ${ }^{14}$ ARIA was developed by the National Centre for the Social Applications 


\begin{tabular}{l}
\hline Table 1 Primary outcome questions at baseline (source: Burgess et al ${ }^{11}$ ) \\
\hline Primary outcome questions \\
\hline Hot beverage scald risk \\
What do you think is the main cause of burns/scalds in children aged 0 -15years in Australia?
\end{tabular}

Note: correct response option is italicised.

of Geographic Information Systems into the following categories: major cities, inner/outer regional and remote/very remote. ${ }^{12}$ SEIFA is based on aggregate area-level socioeconomic status indicators and was categorised into quintiles $(1=$ most disadvantaged, $5=$ least disadvantaged).

Knowledge related to hot beverage scald risk awareness and burn first aid knowledge was assessed by four questions (see table 1). Two multiple choice questions were developed to assess hot beverage scald risk and age group risk awareness: (A) main cause of burns/scalds in children aged 0-15 years; and (B) main age group at risk of any burn/scalds. Children aged $0-2$ years are the most vulnerable, with more children in this age group admitted to hospital for all causes of burns or scalds. Therefore, if participants choose an incorrect answer for the cause of burn question, they were still able to correctly answer the second question on the age group most at risk from any cause of burn/scald. Two questions (informed by previous studies ${ }^{45} 15$ ) assessed burn first aid knowledge: one was open ended, and the other was multiple choice. Correct burn first aid knowledge was defined as cool running water for $20 \mathrm{~min}$, based on evidence of benefit. ${ }^{16-18}$ From these four questions, an overall burn knowledge score out of 4 was computed. Details for scoring are shown in table 1 . For analyses, the burns first aid score was also categorised into a binary variable: adequate (response of 'cool running water for $20 \mathrm{~min}$ ' to the open-ended question) versus inadequate (any other response).

\section{Data analysis}

Data were analysed using IBM SPSS V.24. ${ }^{19}$ Independent samples t-tests (numerical variables) and $\chi^{2}$ tests (categorical variables) were used to determine whether there were any differences between participants with adequate versus inadequate burns first aid knowledge. Logistic regression was conducted to determine whether there were any significant independent predictors of adequate burn first aid knowledge. Factors assessed in univariate analyses included age, education, marital status, country of birth, age of youngest child, first-time mothers, SEIFA level, ARIA category, first aid training, previous burn experience and source of burn first aid information. Variables significantly associated with adequate first aid knowledge in univariate analyses were included in a logistic regression model $(\mathrm{P}<0.05)$. Any variables no longer significant were removed from the model, one at a time, and the impact on the remaining variables was assessed. If no changes to the odds ratios of the other variables beyond $10 \%$ were observed, then the variable was removed.

\section{RESULTS}

In total, 498 participants from Queensland, Australia, completed the baseline questionnaire.

\section{Demographic features}

Sample characteristics are shown in table 2. Almost half (48\%) of participants resided in major cities, $42 \%$ periurban (inner and outer regional areas) and 10\% were from remote/very remote areas. Half (53\%) of participants were aged $<29$ years, $43 \%$ were first-time mothers, 55\% were married and 20\% were current smokers. Education levels varied: approximately equal proportions had completed high school (26\%), an advanced diploma/ Technical and Further Education (TAFE) certificate (26\%) or university/college degree (23\%). The majority $(84 \%)$ of participants were born in Australia; of those born outside Australia, the most common countries of birth were New Zealand (4.6\%) and the UK (4.6\%). Forty-two per cent of participants reported their youngest child regularly spent time each week in the care of another person; the majority of carers were partners $(23 \%)$, followed by childcare centres (19\%), grandparents (16\%), relative/family member (5\%) and older sibling (2\%).

\section{Overall burn knowledge}

Participants' knowledge regarding burns is shown in table 3. The mean overall burn knowledge score was $1.98( \pm \mathrm{SD}=0.89)$. One-third (33\%) of participants responded correctly regarding the leading cause of burns and scalds (hot drinks), while 34\% 
Table 2 Sample characteristics, by adequate versus inadequate burns first aid knowledge

\begin{tabular}{|c|c|c|c|c|}
\hline Sample characteristics & $\begin{array}{l}\text { Adequate } \\
(\mathrm{n}(\%)) \dagger\end{array}$ & $\begin{array}{l}\text { Inadequate } \\
(\mathrm{n}(\%)) \dagger\end{array}$ & & $\begin{array}{l}\text { Total } \\
\text { (n (\%)) }\end{array}$ \\
\hline \multicolumn{5}{|l|}{ Age (years) } \\
\hline $18-24$ & $10(20)$ & $78(18)$ & & 89 (18) \\
\hline $25-29$ & $18(36)$ & $156(35)$ & & $176(35)$ \\
\hline $30-34$ & $14(28)$ & $145(33)$ & & $161(32)$ \\
\hline $35-39$ & 7 (14) & $54(12)$ & & $62(12)$ \\
\hline $40+$ & $1(2)$ & $9(2)$ & & $10(2)$ \\
\hline \multicolumn{5}{|l|}{ Education } \\
\hline$<$ Year 12 & $4(8)$ & $82(19)$ & & $86(17)$ \\
\hline Year 12 completion & $12(24)$ & $117(27)$ & & $131(26)$ \\
\hline $\begin{array}{l}\text { Advanced diploma/TAFE } \\
\text { certificate }\end{array}$ & $13(26)$ & $112(25)$ & & $127(26)$ \\
\hline University degree & $13(26)$ & $99(22)$ & & $112(23)$ \\
\hline Postgraduate & $8(16)$ & $32(7)$ & & $42(8)$ \\
\hline \multicolumn{5}{|l|}{ Marital status } \\
\hline Married & $34(68)$ & $237(54)$ & & $274(55)$ \\
\hline Defacto & $13(26)$ & $127(29)$ & & $142(29)$ \\
\hline Single & $2(4)$ & $64(15)$ & & 67 (14) \\
\hline Divorced/separated & $1(2)$ & $12(3)$ & & $13(3)$ \\
\hline Missing & 0 & $2(0.5)$ & & $2(0.4)$ \\
\hline \multicolumn{5}{|l|}{ Smoking status } \\
\hline Smoker & $2(4)$ & $95(22)$ & ** & $97(20)$ \\
\hline Non-smoker & $48(96)$ & $347(78)$ & & $395(80)$ \\
\hline \multicolumn{5}{|l|}{ Country of birth } \\
\hline Australia & $45(90)$ & $368(84)$ & & 419 (84) \\
\hline New Zealand & $1(2)$ & $22(5)$ & & $23(5)$ \\
\hline UK & $1(2)$ & $22(5)$ & & $23(5)$ \\
\hline Other & $3(6)$ & $24(6)$ & & $27(7)$ \\
\hline \multicolumn{5}{|l|}{ SEIFA $\ddagger$} \\
\hline 1 (most disadvantaged) & $9(18)$ & $52(12)$ & & $62(13)$ \\
\hline 2 & $13(26)$ & $71(16)$ & & $83(17)$ \\
\hline 3 & $9(18)$ & $101(23)$ & & $110(22)$ \\
\hline 4 & $12(24)$ & $166(38)$ & & $178(36)$ \\
\hline 5 (least disadvantaged) & $7(14)$ & $49(11)$ & & $57(12)$ \\
\hline \multicolumn{5}{|l|}{ ARIA§ } \\
\hline Urban (major cities) & $22(44)$ & $212(48)$ & & $238(48)$ \\
\hline $\begin{array}{l}\text { Periurban (inner/outer } \\
\text { regional) }\end{array}$ & $26(52)$ & $179(41)$ & & $205(42)$ \\
\hline Remote/very remote & $2(4)$ & $48(11)$ & & $49(10)$ \\
\hline $\begin{array}{l}\text { Age of youngest child } \\
5-6 \text { months }\end{array}$ & $14(28)$ & $119(27)$ & & $134(27)$ \\
\hline 7-8 months & $6(12)$ & $61(14)$ & & $67(13)$ \\
\hline 9-10months & $4(8)$ & $64(14)$ & & 70 (14) \\
\hline $11-12$ months & $26(52)$ & $198(45)$ & & $227(46)$ \\
\hline First-time mothers & $24(48)$ & $188(43)$ & & $216(43)$ \\
\hline \multicolumn{5}{|c|}{ Child under regular care of another person } \\
\hline Yes & $29(58)$ & $177(40)$ & * & $210(42)$ \\
\hline No & $21(42)$ & $265(60)$ & & $286(58)$ \\
\hline $\begin{array}{l}\text { First aid training in past } \\
12 \text { months } \\
\text { Yes }\end{array}$ & $23(46)$ & $86(19)$ & $* * *$ & $112(22)$ \\
\hline No & $27(54)$ & $356(81)$ & & $386(77)$ \\
\hline \multicolumn{5}{|l|}{ Previous experience with burn } \\
\hline Yes & $26(52)$ & $210(47)$ & & $238(48)$ \\
\hline No & $24(48)$ & $232(53)$ & & $260(52)$ \\
\hline \multicolumn{5}{|c|}{ Source of information regarding burns first aidף } \\
\hline Internet & $40(80)$ & $348(79)$ & & $388(79)$ \\
\hline
\end{tabular}

Table 2 Continued

\begin{tabular}{lccc}
\hline Sample characteristics & $\begin{array}{l}\text { Adequate } \\
(\mathbf{n}(\%)) \dagger\end{array}$ & $\begin{array}{l}\text { Inadequate } \\
(\mathbf{n}(\%)) \dagger\end{array}$ & $\begin{array}{l}\text { Total } \\
(\mathbf{n}(\%))\end{array}$ \\
\hline Family/friends & 0 & $44(10)$ & $44(9)$ \\
Books & $5(10)$ & $30(7)$ & $35(7)$ \\
Other & $5(10)$ & $20(4)$ & $25(5)$ \\
\hline
\end{tabular}

${ }^{*} \mathrm{P}<0.05,{ }^{* *} \mathrm{P}<0.01,{ }^{* *} \mathrm{P}<0.001$.

tMissing first aid data from six participants excluded.

¥Socioeconomic Index For Areas (SEIFA) was used to estimate socioeconomic status in this study. Specifically, the Index of Relative Socioeconomic Advantage and Disadvantage. Higher deciles reflect higher relative advantage, and lower deciles reflect lower relative advantage. Deciles were reduced to five categories. $\S$ Location of usual residence was categorised using Accessibility/Remoteness Index of Australia (ARIA) developed by National Centre for the Social Applications of Geographic Information Systems. Each geographical area was allocated a score between 0 and 15, based on the (road) distance to nearby towns that provide services. Scores were then allocated to the following categories (OESR Queensland, 2011): urban (major city: 0.0-0.2); periurban (inner regional: 0.2-2.4; outer regional: 2.4-5.92); and remote (remote: $5.92-10.53$; very remote: $10.53+$ ). IB Because there are no values in the 'family/friends' category of this variable, no statistical test is valid.

incorrectly selected baths/taps. Forty-four per cent of participants correctly selected children aged $0-2$ years as the age group most at risk of burns and scalds, while $54 \%$ incorrectly selected children aged $2-5$ years.

\section{Burn first aid knowledge}

The most common source of burn first aid information was the internet (79\%), followed by friends/family (9\%), then first aid books (7\%). Twenty-three per cent of participants had undertaken first aid training in the past 12 months.

Overall, $94 \%$ of participants reported they would use cool/ cold water to treat a burn. One in 10 participants gave the correct duration for applying cool running water unprompted, 9\% reported the incorrect duration and $74 \%$ did not specify a time. Of those who did not report a time for applying water $(n=371)$, $44 \%$ provided the correct duration time when prompted with the multiple-choice question. An additional $28 \%$ chose ' $6-10$ min' (11-15 min: 15\%; 1-5 min: 11\%). Of the participants who reported an incorrect duration in the unprompted question $(n=43), 21 \%$ correctly responded to the prompted multiple-choice question (6-10 min: 44\%; 11-15 min: 19\%; 1-5 min: $16 \%)$. Eight participants (2\%) mentioned removing clothing/ jewellery from the burn area, while two participants suggested leaving clothes on.

\begin{tabular}{|c|c|}
\hline Overall burn knowledge (mean (SD)) & $1.98( \pm S D$ 0.891) \\
\hline \multicolumn{2}{|l|}{ Burn first aid knowledge (n (\%)) } \\
\hline Cool running water $20 \mathrm{~min}$ —unprompted & $50(10.2)$ \\
\hline Cool running water $20 \mathrm{~min} —$ prompted & $164(33.3)$ \\
\hline Cool running water-incorrect duration & $250(50.8)$ \\
\hline Other treatment or unsure & $28(5.7)$ \\
\hline \multicolumn{2}{|l|}{ Optimal first aid ( $(\%))$} \\
\hline Adequate (cool running water for $20 \mathrm{~min}$ ) & $50(10.2)$ \\
\hline Inadequate (any other response) & $442(88.8)$ \\
\hline \multicolumn{2}{|l|}{ Burn risk factors (n (\%)) } \\
\hline $\begin{array}{l}\text { Correct main cause of burns/scalds in children (hot } \\
\text { beverage scalds) }\end{array}$ & $164(32.9)$ \\
\hline Correct age group most at risk ( $0-2$ years) & $218(43.8)$ \\
\hline
\end{tabular}


Burn first aid knowledge was categorised into adequate (cool running water for $20 \mathrm{~min}$ in the unprompted question) versus inadequate (any other response). Almost 90\% (88.8\%; $\mathrm{n}=442$ ) of the sample demonstrated inadequate burn first aid knowledge. As shown in table 2, knowledge of burn first aid was associated with smoking status $\left(\chi^{2}=8.68 ; \mathrm{df}=1 ; \mathrm{P}=0.003\right)$, first aid training the past 12 months $\left(\chi^{2}=18.35 ; \mathrm{df}=1 ; \mathrm{P}<0.001\right)$ and whether the child regularly spent time under the care of someone else $\left(\chi^{2}=5.95 ; \mathrm{df}=1 ; \mathrm{P}=0.015\right)$. No other variables were associated with burn first aid knowledge $(\mathrm{P}>0.05)$.

Of interest is that among those who had completed first aid training in the past 12 months $(n=109), 79 \%$ demonstrated inadequate burn first aid knowledge. All participants who reported family/friends as their primary source of first aid information demonstrated inadequate burn first aid knowledge. There was no association between previous personal burn/scald experience (of self or child) and adequate burn first aid knowledge (52\% adequate vs $47.5 \%$ inadequate).

The final logistic regression model comprised only two variables. (While three variables were significant in crude analyses, one variable-whether the child regularly spent time under the care of someone else-was not significant when entered into the final logistic regression model and removing it did not change the remaining ORs more than $10 \%$, so it was not retained). Hence, only two independent predictors of adequate burn first aid knowledge were identified from these data. Mothers with adequate burn first aid knowledge were 3.32 times more likely to have had first aid training in the past 12 months $(95 \%$ CI 1.8 to 6.1), and 5.98 times more likely to be non-smokers (95\% CI 1.4 to 25.2 ) than mothers with inadequate burn first aid knowledge.

\section{Burn first aid knowledge and burn risk factors}

The association between burn first aid knowledge and burn risk factors was also assessed. Half of participants who demonstrated adequate burn first aid knowledge correctly identified hot beverage scalds as the main cause of burns/scalds in children, compared with $31.4 \%$ of those with inadequate burn first aid knowledge $\left(\chi^{2}=5.95 ; \mathrm{df}=1 ; \mathrm{P}=0.008\right)$. There was no association between age group most at risk and adequate burn first aid knowledge $(\mathrm{P}>0.05)$.

\section{DISCUSSION}

This study demonstrates mothers of young children are largely unaware how frequently hot beverage scalds occur and the age group most susceptible to them. It also demonstrates an overall gap in knowledge about correct burn first aid treatment.

\section{Burn risk}

Most injuries to children under 4 years of age occur in the child's home ${ }^{20}$ yet a recent study found that $77 \%$ of parents consider their homes to be safer than most. ${ }^{21}$ The majority of hot beverage scalds occur in the child's home, predominantly in the kitchen, and are often witnessed by an adult. ${ }^{39}$ Lack of supervision is often noted in the literature as a contributing factor to preventable injuries in children. ${ }^{22}$ However, a previous study by the authors found the majority of hot beverage scalds to children under 36 months occurred when the parent/caregiver was within arm's reach of the child. ${ }^{24}$

In the current study, two-thirds of participants did not know that hot beverage scalds are the main cause of burns to children, and less than half recognised that children under 2 years are most at risk. The data reported in this study indicate that messages regarding hot beverage scalds as the leading cause of burns to children and the main age group at risk have not been translated to the relevant target group (mothers of young children), potentially making parents and caregivers of young children less vigilant in keeping hot drinks out of reach around infants and toddlers.

\section{Burn first aid}

Preventing hot beverage scalds is one part of the equation, with secondary prevention through correct burn first aid the other. There is strong evidence to show that adequate burn first aid treatment (cool running water for $20 \mathrm{~min}$ ) applied within 3 hours of the burn occurring has a significant impact on wound healing by reducing burn depth, providing pain relief, faster re-epithelialisation, improved scar management, shorter hospital stays and fewer surgical interventions. ${ }^{16-1825}$

The low knowledge of correct burn first aid reported by mothers of young children in this study is consistent with many other studies that show the general public is largely unaware how to treat a burn. ${ }^{4526}$ Unprompted, 94\% of participants in this study reported using water to treat a burn but only $10 \%$ of participants knew to apply it for $20 \mathrm{~min}$. When prompted this increased to $44 \%$. These results are similar to other studies. ${ }^{525}$ The general public appear to be unaware of the evidence around applying cool running water for $20 \mathrm{~min}$. This is not surprising given the primary source of first aid information for many parents is the internet. Two studies have looked at the quality of burn first aid information online, and both concur that the information is overwhelmingly inaccurate, inadequate and inconsistent. $^{27} 28$ The inconsistencies are also apparent among global burn advisory agencies, ${ }^{29}$ which can add to confusion when searching online. It is important that parents and caregivers of young children are aware of correct burn first aid given that most of these injuries occur in the home. For mothers of very young children who are most at risk of hot beverage scalds, education about this simple method of treating a burn should it occur can be empowering.

The Health Belief Model $^{30}$ suggests that for a behaviour change to succeed, individuals must have the incentive to change, must feel threatened by their current behaviour and must feel that a change will be beneficial. ${ }^{31}$ In terms of preventative efforts by mothers with regard to any burn, prevention strategies must increase their beliefs about their child's risk of a burn injury while simultaneously increasing their competency to intervene or act quickly and appropriately should a burn occur. ${ }^{32}$

Raising mothers' awareness of the frequency and severity of hot beverage scalds, and the peak occurrence in children under 2 years, will better prepare them to take preventative measures to keep their child safe.

After adjusting for all relevant variables, the only two independent predictors of adequate burn first aid knowledge were first aid training in the past 12 months and smoking behaviour. In other words, there were no associations between any of the demographic variables such as age of mother, age of child, number of other children, socioeconomic status, education, relationship status and adequate burn first aid knowledge. This highlights that inadequate burn first aid knowledge is prevalent across this target group (mothers of young children) and that there is an urgent and compelling need to improve knowledge of burn first aid in this group.

Also of interest was the finding that previous personal burn/ scald experience (of self or child) did not improve burn first aid knowledge. This may indicate an opportunity for intervention to increase knowledge of caregivers of children who experience 
a burn in order to prevent future burns. However, the question did not allow for assessment of the severity of the previous burn. It may be that caregivers of children who sustain a burn that is serious enough to seek medical attention already receive such education.

Also of considerable concern is that, while first aid training in the previous 12 months was associated with adequate burn first aid knowledge, a substantial proportion (79\%) of mothers who had participated in recent first aid training demonstrated inadequate burn first aid knowledge. Further research is required to explore this.

\section{Limitations}

The findings of this study should be interpreted in the context of several limitations. First, participants were recruited via social media. Hence, there is potential for selection bias, and it is possible that the findings cannot be generalised beyond the study population to the target group (mothers of young children in Queensland). However, mothers with young children are the most active on social media, ${ }^{33}$ and participants were representative of the target population (women who birthed in Queensland in 2015) with regard to age, marital status, being a first-time mother and country of birth. ${ }^{34}$ However, participants living in remote and very/remote areas were over-represented ( $10 \%$ vs $3.3 \%$ total). ${ }^{35}$ People who could not understand English are less likely to have participated in this study. The risks are higher for these people, ${ }^{67}$ so in this respect, our findings may be conservative. Second, information was collected via the app on the smartphone, hence there is potential for measurement bias (eg, self-report and/or recall bias). While the questions were mostly demographic, with low potential for measurement bias, there is evidence of underestimation of smoking by self-report ${ }^{36}$; therefore, additional undeclared smokers may have been included.

\section{What is already known on the subject}

- Hot beverage scalds are the leading cause of burns in children.

- The burden of hot beverage scalds goes beyond the physical suffering of the child; the financial and psychological burden can also be significant.

- Applying correct burn first aid (20 min cool running water) within 3 hours of a burn occurring can significantly improve injury outcomes.

\section{What this study adds}

- Mothers of young children are largely unaware of the frequency and severity of hot beverage scalds.

- There is a very low level of correct burn first aid knowledge among mothers of young children, with very few independent predictive factors. Inadequate burn first aid knowledge is prevalent across this target group. There is an urgent and compelling need to improve knowledge of burns first aid in mothers of young children generally.

- The primary source of information for burns first aid is the internet.

\section{CONCLUSION}

Mothers of young children appear largely unaware of the frequency with which hot drink scalds occur in children under 2 years of age and overall demonstrate inadequate knowledge of burns first aid. Increasing their knowledge and awareness about the risks associated with these injuries is crucial so they can take preventative actions. Interventions aimed at preventing these scalds should also include a burn first aid component. After adjusting for all relevant variables, the only two independent predictors of adequate burn first aid knowledge were first aid training in the past 12 months and smoking behaviour. This highlights that inadequate burn first aid knowledge is prevalent across this target group (mothers of young children) and that there is an urgent and compelling need to improve knowledge of burns first aid in this group generally. As demonstrated in this and many other studies, knowledge of correct burn first aid is lacking. Equipping mothers, parents and caregivers of young children with this information will lead to improved injury outcomes should a burn/scald injury occur.

Contributors We confirm that all authors have made substantial contributions to all of the following: (1) the conception and design of the study, or acquisition of data, or analysis and interpretation of data, (2) drafting the article or revising it critically for important intellectual content and (3) final approval of the version to be submitted.

\section{Competing interests None declared.}

Ethics approval This study was approved by the University of Queensland Institutional Human Research Ethics Committee (approval number: 2015001652).

Provenance and peer review Not commissioned; externally peer reviewed.

(c) Article author(s) (or their employer(s) unless otherwise stated in the text of the article) 2018. All rights reserved. No commercial use is permitted unless otherwise expressly granted.

\section{REFERENCES}

1 Turner C, Spinks A, McClure R, et al. Community-based interventions for the prevention of burns and scalds in children. In: The Cochrane Collaboration, ed. Cochrane Database Syst Rev. Chichester, UK: John Wiley \& Sons, Ltd, 2004

2 Zou K, Wynn PM, Miller P, et al. Preventing childhood scalds within the home: overview of systematic reviews and a systematic review of primary studies. Burns 2015:41:907-24.

3 Burgess JD, Kimble RM, Cameron CM, et al. Hot beverage scalds in australian Children: still simmering 10 years on. J Burn Care Res 2016;37:e335-9.

4 Davies M, Maguire S, Okolie C, et al. How much do parents know about first aid for burns? Burns 2013;39:1083-90.

5 Harvey LA, Barr ML, Poulos RG, et al. A population-based survey of knowledge of first aid for burns in New South Wales. Med J Aust 2011;195:465-8.

6 Riedlinger DI, Jennings PA, Edgar DW, et al. Scald burns in children aged 14 and younger in Australia and New Zealand - an analysis based on the burn registry of Australia and New Zealand (BRANZ). Burns 2015;41:462-8.

7 Hyland EJ, Harvey JG, Holland AJ. First aid for burns: too little, too late and often wrong. Med J Aust 2014;200:85.

8 Stockton KA, Harvey J, Kimble RM. A prospective observational study investigating all children presenting to a specialty paediatric burns centre. Burns 2015;41:476-83.

9 Dewar DJ, Magson CL, Fraser JF, et al. Hot beverage scalds in Australian children. J Burn Care Rehabil 2004;25:224-7.

10 Hankins $\mathrm{CL}$, Tang XQ, Phipps A. Hot beverage burns: an 11-year experience of the yorkshire regional burns centre. Burns 2006;32:87-91.

11 Burgess JD, Cameron CM, Watt K, et al. Cool runnings - an app-based intervention for reducing hot drink scalds: study protocol for a randomised controlled trial. Trials 2016;17:388.

12 Geographic Information Systems, ARIA and Accessibility. Hugo centre for migration and population research. http://www.adelaide.edu.au/apmrc/research/projects/ category/aria.html (accessed 13 June 2017).

13 Queensland Government. Office of Economic and Statistical Research. Accessibility and remoteness index of Australia. 2012 http://www.oesr.qld.gov.au/about-statistics/ statistical-standards/national/aria.php (accessed 29 May 2013).

14 Australian Bureau of Statistics. Census of population and housing: socio-economic indexes for areas (SEIFA), Australia. 2011 http://www.abs.gov.au/websitedbs/ censushome.nsf/home/seifa2011 (accessed 1 May 2017).

15 Elkington J. Evaluation of a statewide campaign to prevent scalds in young children. N S W Public Health Bull 1999;10:126. 
16 Wood FM, Phillips M, Jovic T, et al. Water first aid is beneficial in humans post-burn: evidence from a bi-national cohort study. PLoS One 2016;11:e0147259.:e0147259.

17 Cuttle L, Kempf M, Kravchuk O, et al. The optimal temperature of first aid treatment for partial thickness burn injuries. Wound Repair Regen 2008;16:626-34.

18 Cuttle L, Kempf M, Liu PY, et al. The optimal duration and delay of first aid treatment for deep partial thickness burn injuries. Burns 2010;36:673-9.

19 IBM SPSS. IBM corporation. Armonk, NY, USA.

20 Peden MM. World report on child injury prevention. Geneva: World Health Organization, 2008. http://apps.who.int/iris/bitstream/10665/43851/1/ 9789241563574_eng.pdf. (accessed 3 April 2016).

21 Safe Kids Worldwide. Report to the nation: protecting children in your home (february 2015). 2015 https://www.safekids.org/research-report/report-nation-protectingchildren-your-home-february-2015 (accessed 30 April 2017).

22 Morrongiello BA, Schell SL. Child Injury: the role of supervision in prevention. Am J Lifestyle Med 2010;4:65-74.

23 Saluja G, Brenner R, Morrongiello BA, et al. The role of supervision in child injury risk: definition, conceptual and measurement issues. Inj Contro/ Saf Promot 2004;11:17-22.

24 Burgess JD, Kimble RM, Watt KA, et al. Hot tea and tiny tots don't mix: A crosssectional survey on hot beverage scalds. Burns 2017;43:1809-16.

25 Cuttle $L$, Kravchuk $O$, Wallis $B$, et al. An audit of first-aid treatment of pediatric burns patients and their clinical outcome. J Burn Care Res 2009;30:1028-34.

26 Graham HE, Bache SE, Muthayya P, et al. Are parents in the UK equipped to provide adequate burns first aid? Burns 2012;38:438-43.
27 Burgess JD, Cameron CM, Cuttle L, et al. Inaccurate, inadequate and inconsistent: a content analysis of burn first aid information online. Burns 2016;42:1671-7.

28 Tiller G, Rea S, Silla R, et al. Burns first aid information on the Internet. Burns 2006:32:897-901.

29 Zideman DA, De Buck ED, Singletary EM, et al. European resuscitation council guidelines for resuscitation 2015 section 9. first aid. Resuscitation 2015;95:278-87.

30 Rosenstock IM. Historical origins of the health belief model. Health Educ Monogr 1974;2:328-35.

31 Egger G, ed. Health promotion strategies \& methods. Rev. Sydney, New York: McGraw-Hill, 1999.

32 Sleet DA, Carlson Gielen A, Diekman S, et al. preventing unintentional injury: a review of behavior change theories for primary care. Am J Lifestyle Med 2010;4:25-31.

33 Sify News. Mothers with children under 5 most active on social media. http://www. sify.com/news/mothers-with-children-under-5-most-active-on-social-media-newsinternational-nlgna6jiccesi.html (accessed 1 May 2017).

34 Queensland Perinatal Data Collection. Queensland perinatal statistics 2015. 2015 https://www.health.qld.gov.au/hsu/peri/peri2015/report2015 (accessed 9 Aug 2017).

35 Australian Bureau of Statistics. 4102.0 - Australian social trends, population distribution. http://www.abs.gov.au/AUSSTATS/abs@.nsf/Lookup/4102. OChapter3002008 (accessed 8 June 2017).

36 Connor Gorber S, Schofield-Hurwitz S, Hardt J, et al. The accuracy of self-reported smoking: a systematic review of the relationship between self-reported and cotinineassessed smoking status. Nicotine Tob Res 2009;11:12-24. 